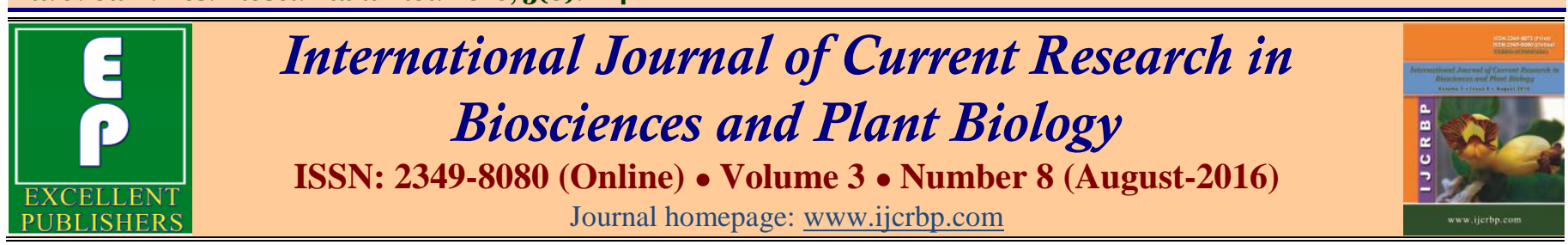

\title{
Free Radical Scavenging Activity of Sida cordifolia Linn. Extracts Measured by Hydrogen Peroxide, DPPH, ABTS and Ferric Reducing Antioxidant Methods
}

\author{
Mradu Gupta $^{1 *}$, Suhrita Paul ${ }^{2}$, Nandita Karmakar ${ }^{1}$, Saswati Sasmal ${ }^{1}$ and Saikat Chowdhury ${ }^{1}$ \\ ${ }^{1}$ Institute of Post Graduate Ayurvedic Education and Research, 294/3/1, A. P. C. Road, Kolkata-70o 0o9, India \\ ${ }^{2}$ Calcutta Medical College, 88, College Street, Kolkata-70o 073, India
}

*Corresponding author.

\begin{abstract}
Antioxidants inhibit free radical reactions in our body and prevent cellular damage. Plant based polyphenols and flavonidic substances have been known as good antioxidants. Sida cordifolia Linn. exhibits many therapeutic pharmacological properties such as wound healing, anti-microbial, anti-inflammatory and hepato-protective due to presence of many polyphenols and flavonoids in its roots and seeds. Antioxidant capacities of aqueous and alcoholic (ethanol) extracts of Sida cordifolia roots were evaluated using in vitro standard procedures by assessing their free radical scavenging capacities. Total phenol content was assessed as 18.70 and $23.26 \mathrm{GAE} / \mathrm{mg}$ while the total flavonoid content was found to be 15.03 and $6.62 \mathrm{QE} / \mathrm{mg}$ for alcoholic and aqueous extract respectively. $\mathrm{IC}_{50}(\mu \mathrm{g} / \mathrm{ml})$ of alcoholic extract, aqueous extract and ascorbic acid was found to be $36.189 \pm 0.993,31.297 \pm 2.791$ and $15.503 \pm 1.356$ respectively in hydrogen peroxide radical scavenging, $1.520 \pm 0.075,1.027 \pm 0.012$ and $0.879 \pm 0.273$ in DPPH radical scavenging assay, and $232 \pm 15.163,179 \pm 53.894$ and $6.627 \pm 0.061$ during FRAP essay. Similarly, during ABTS radical scavenging assay, $\mathrm{IC}_{50}(\mu \mathrm{g} / \mathrm{ml})$ was assessed as $332.960 \pm 2.177,162.155 \pm 9.736$ and $6.779 \pm 0.167$ for alcoholic, aqueous extract and Trolox respectively. While both extracts showed significant free radical scavenging activity, the aqueous extract exhibits higher activity than alcoholic extract.
\end{abstract}

\section{Introduction}

Antioxidants are molecules that inhibit or quench free radical reactions and delay or inhibit cellular damage. Though the antioxidant defenses are different from species to species, the presence of the antioxidant defense is universal. Antioxidants exist both in enzymatic and non -enzymatic forms in the intracellular and extracellular environment. Enzymatic antioxidants work by breaking down and removing free radicals. The antioxidant enzymes convert dangerous oxidative products to hydrogen peroxide $\left(\mathrm{H}_{2} \mathrm{O}_{2}\right)$ and then to water, in a multi-step process in presence of cofactors such as copper, zinc, manganese, and iron. Non-enzymatic antioxidants work by interrupting free radical chain reactions.

Normal biochemical reactions, increased exposure to the environment and higher levels of dietary xenobiotics result in the generation of reactive oxygen species (ROS) and reactive nitrogen species (RNS). ROS and RNS are responsible for the oxidative stress in different pathophysiological conditions. Cellular constituents of our body are altered in oxidative stress conditions, resulting in 
various disease states. The oxidative stress can be effectively neutralized by enhancing cellular defenses in the form of antioxidants. Reactive oxygen species (ROS), including superoxide radicals $\left(\cdot \mathrm{O}^{2-}\right)$, hydrogen peroxide $\left(\mathrm{H}_{2} \mathrm{O}_{2}\right)$, hydroxyl radicals $(\cdot \mathrm{OH})$, and singlet oxygen $\left({ }_{1} \mathrm{O}_{2}\right)$, are generated as byproducts of normal metabolism (Wang and Jiao, 2000; Živković et al., 2010).

To counteract the deleterious effects of ROS, phenolic compounds which are naturally distributed in plants are very effective (Chung et al., 1998). The food-derived antioxidants such as vitamins and phenolic phytochemicals have received growing attention because they are known to function as chemo-preventive agents against oxidative damage. Polyphenols are considered to be plant chemical defenses against pathogens and herbivores, and these compounds can exert detrimental effects in a multitude of ways (Bernays et al., 1989). Polyphenols have many favourable effects on human health, such as the inhibition of the low density proteins oxidization (Frankel et al., 1993). They also have antiinflammatory activity and anti-carcinogenic properties (Miyake et al., 1999).

Sida cordifolia Linn. belonging to the family, Malvaceae is one of the most useful medicinal plants in Ayurvedic literature. Also known as Bala, it is a small, erect, annual downy shrub. The leaves of the plant are chordateoblong or ovate-oblong and fruits with a pair of awns on each carpel. The tap root of the plant is odourless with slightly bitter taste and grayish yellow colour which constitute a cluster $5-15 \mathrm{~cm}$ long with few lateral roots of smaller size. It has been used as a cooling, astringent, aromatic, stomachic, diuretic and tonic in Ayurvedic system of medicine for curing of diseases like asthma, cough, fever, wound, skin diseases, heart diseases, facial paralysis, muscle and joint pain, swelling, inflammation, urinary infection, skin diseases, lack of sexual desire and unwanted weight loss. Its roots and seeds contain alkaloid ephedrine, vasicinol, vasicinone, $\beta$-sitosterol and stigmasterol and $\mathrm{N}$-methyl tryptophan while the leaves of Sida cordifolia contain small amounts of both ephedrine and pseudoephedrine. Its pharmacological actions include hypoglycaemic, wound healing, anti-microbial, antioxidant, anti-inflammatory, analgesic, adaptogenic and hepato-protective activities (Sharma, 1995; Jain et al., 2011; Sharma et al., 2001; Shastri, 1988; Chatterjee and Pakrashi, 1992; Kirtikar and Basu, 1989).

During the present study, the aqueous and alcoholic extracts of the roots of Sida cordifolia were screened for their antioxidant capacities using in vitro standard procedures after assessing its phenolic and flavonoid contents. The objective of the research was to assess the medicinal potential of this plant, especially its antioxidant potential in the form of free radical scavenging activity, using scientific techniques and thus justify its traditional and folklore use as a substantial and efficacious reliable rejuvenator herbal formulation.

\section{Materials and methods}

\section{Plant materials}

The roots of Sida cordifolia Linn. were purchased from crude drug supplier of Katwa Chowrasta, Burdwan district and the plant samples were authenticated by the Research Officer, Botanical Survey of India, Howrah, India.

\section{Chemicals}

Potassium Sodium Tertrate, Aluminium chloride, FolinCiocalteu's reagent, sodium carbonate, Sulphuric acid, Hydrogen peroxide, Ferric Chloride ( $\mathrm{FeCl} 3)$, Di-Sodium hydrogen Phosphate and Butylated hydroxytoluene (BHT) were obtained from Merck Specialties Pvt. Ltd., Mumbai, India. 2, 2- azinobis (3 ethyl-benzothiazoline-6sulfonic acid) [ABTS] was obtained from Roche diagnostics, Mannheim, Germany while 6-hydroxy2,5,7,8- tetramethylchroman-2-carboxylic acid (Trolox) was obtained from Fluka, Buchs, Switzerland. Quercetin was purchased from Sisco Research Laboratories Pvt. Ltd., Mumbai, India. Gallic acid, Ascorbic acid, Potassium persulphate, Potassium ferricyanide and Trichloro acetic acid were obtained from Nice Chemicals Pvt. Ltd. Kochi, Kerala, India. Sodium phosphate was obtained from Sarabhai M. Chemicals Limited, Shantisadan, Ahmedabad, Gujarat, India and Ammonium molybdate was obtained from GFS chemicals, United States. 1,1-diphenyl-2-picrylhydrazyl (DPPH) was purchased from MP Biomedicals, France.

\section{Preparation of extracts}

The roots of Sida cordifolia were washed, sun dried and crushed to particle size of 40 mesh. This coarse powder was sequentially extracted with petroleum ether $\left(60^{\circ} \mathrm{C}\right.$ $80^{\circ} \mathrm{C}$ ), chloroform, acetone, ethanol and water using Soxhlet apparatus. These extracts were filtered using a Buckner funnel and Whatman No. 1 filter paper at room temperature and concentrated at reduced temperature and pressure using rotary evaporator. All obtained extracts 
were stored in refrigerator below $10^{\circ} \mathrm{C}$ for subsequent experiments. The aqueous and alcoholic (ethanol) extracts of the roots of Sida cordifolia were used in the study.

\section{Total phenol content}

Total phenol content was determined using the FolinCiocalteu reagent. To $0.5 \mathrm{ml}$ aliquot of dried aqueous extract of Sida cordifolia, $2.5 \mathrm{ml}$ of Folin-Ciocalteu's reagent (10\%) and $2 \mathrm{ml}$ of $7.5 \%$ sodium carbonate were added. The absorbance was read after $30 \mathrm{~min}$ incubation period at room temperature at $760 \mathrm{~nm}$ colorimetrically. A standard calibration plot was generated at $760 \mathrm{~nm}$ using known different concentrations of Gallic acid (100, 200, 300,400 , and $500 \mu \mathrm{g} / \mathrm{ml}$ ). The concentrations of phenol in the test samples were calculated from the calibration plot. Total phenolic content was expressed as mg Gallic Acid Equivalents (GAE). All determinations were performed in triplicates and the results were expressed as mg Gallic acid equivalents per gram sample extract (Baba and Malik, 2015; Harborne, 1984).

\section{Total flavonoid content}

Total Flavonoid content was determined using the Aluminum chloride $\left[\mathrm{AlCl}_{3}\right]$ method. Briefly, an aliquot of $0.5 \mathrm{ml}$ of sample $(1 \mathrm{mg} / \mathrm{ml})$ was mixed with $1.5 \mathrm{ml}$ of methanol, $0.1 \mathrm{ml}$ of $1 \%$ aluminum chloride and $0.1 \mathrm{ml}$ of potassium acetate solution $(1 \mathrm{M})$. In the mixture, $2.8 \mathrm{ml}$ of distilled water was added to bring up the total volume to $5 \mathrm{ml}$. The test solution was shaken vigorously and Absorbance at $415 \mathrm{~nm}$ was recorded after 30 minutes of incubation. A standard calibration plot was generated at $415 \mathrm{~nm}$ using different and known concentrations of Quercetin. The concentrations of flavonoid in the test samples were calculated from the calibration plot and expressed as $\mathrm{mg}$ Quercetin equivalent/g of sample (Chang et al., 2002; Usha Sri et al., 2012).

\section{Hydrogen peroxide radical scavenging}

The ability of the extracts to scavenge hydrogen peroxide was determined according to the method of Keser et al. (2012). A solution of hydrogen peroxide $(40 \mathrm{mM})$ was prepared in phosphate buffer $(\mathrm{pH} 7.4)$. Alcoholic and Aqueous extracts $(24.94,49.75$ and $74.44 \mu \mathrm{g} / \mathrm{ml})$ were added to hydrogen peroxide solution $(0.6 \mathrm{ml}, 40 \mathrm{mM})$. Absorbance of hydrogen peroxide at $230 \mathrm{~nm}$ was determined spectro-photometrically by UV-VIS (Shimadzu UV 2450) 10 minutes later against a blank solution containing the phosphate buffer without hydrogen peroxide and compared with ascorbic acid (12.42, 24.69, 36.81 and 48.78 and $74.44 \mu \mathrm{g} / \mathrm{ml})$, the reference compound. The percentage of hydrogen peroxide scavenging of extracts and standard compounds were calculated as follows (Basniwal et al., 2009; Nishaa et al., 2012):

$$
\% \text { scavenged }\left[\mathrm{H}_{2} \mathrm{O}_{2}\right]=\frac{\text { Absorbance of control }- \text { Absorbance of sample }}{\text { Absorbance of control }} \times 100
$$

\section{DPPH radical scavenging assay}

DPPH [1, 1-di-phenyl-2-picryl hydrazyl] is a stable free radical with purple color, the intensity of which is measured spectrophotometrically at $517 \mathrm{~nm}$ wavelength. Antioxidants reduce DPPH to 1, 1-diphenyl-2-picryl hydrazine, a colorless compound. Ascorbic acid was used as standard due to its strong reducing power and weak metal-chelating ability.

The DPPH $0.1 \mathrm{mM}$ solution in ethanol was prepared. This solution $(3 \mathrm{ml})$ was added to $1 \mathrm{ml}$. of alcoholic and aqueous extracts at different concentrations $(0.5,1.0$ and $2.0 \mathrm{mg} / \mathrm{ml}$ ). The mixture was shaken vigorously and allowed to stand at room temp in dark for $30 \mathrm{~min}$. and thereafter the absorbance was measured at $517 \mathrm{~nm}$ by using spectrophotometer (UV-VIS Shimadzu UV 2450) (Anil et al., 2011; Ozcelik et al., 2003). Reference standard compound being used was ascorbic acid with different concentrations $(0.050,0.100,0.150$ and 0.200 $\mathrm{mg} / \mathrm{ml}$ ) and experiment was done in triplicate. The $\mathrm{IC}_{50}$ value of the sample, which is the concentration of sample required to inhibit $50 \%$ of the DPPH free radical, was calculated using inhibition curve. Lower absorbance of the reaction mixture indicated higher free radical activity. Linear graph of concentration vs. percentage inhibition was prepared using various concentrations of Ascorbic acid and $\mathrm{IC}_{50}$ values were calculated.

The percent DPPH scavenging effect was calculated by using the following equation:

$$
\% \text { inhibition }=\frac{\text { Blank }- \text { Extract or Standard }}{\text { Blank }} \times 100
$$

Where, Blank was the absorbance of the control and the absorbance in the presence of the sample was denoted by Extract or Standard.

\section{ABTS radical scavenging assay}

ABTS $\quad(2, \quad 2$ '-azinobis-3-ethylbenzothiozoline-6sulphonic acid) assay is based on the scavenging of 
ABTS radicals. For ABTS assay, the working solution was prepared by mixing equal quantities of $7.4 \mathrm{mM}$ ABTS solution and $2.6 \mathrm{mM}$ potassium persulfate solution and allowing them to react for 12 hours at room temperature in the dark. The solution was then diluted by mixing $1 \mathrm{~mL}$ ABTS solution with $60 \mathrm{~mL}$ methanol to obtain an absorbance of 0.7 to 0.8 units at $734 \mathrm{~nm}$ using the spectrophotometer (UV-VIS Shimadzu UV 2450). Fresh ABTS solution was prepared for each assay and used as Blank (Tupe et al., 2013; Re et al, 1999).

Alcoholic and aqueous extracts with different concentrations (200, 300 and $400 \mu \mathrm{g} / \mathrm{ml}$ ) were allowed to react with $2.94 \mathrm{ml}$ of the ABTS solution for $6 \mathrm{~min}$ in a dark condition. Trolox (water-soluble analog of vitamin E) in different concentrations $(2.70,4.05,8.10$ and 10.80 $\mu \mathrm{g} / \mathrm{ml}$ ) was used as a standard and the same procedure was used. Then the absorbance was measured at $734 \mathrm{~nm}$ using the spectrophotometer. Results were expressed in $\mathrm{mM}$ Trolox equivalents (TE)/g fresh mass. Additional dilution was needed if the ABTS value measured was over the linear range of the standard curve. $\mathrm{IC}_{50}$ value (concentration of sample where absorbance of ABTS decreases $50 \%$ with respect to absorbance of blank) of the sample was determined.

Scavenging ability relative to the reaction control (without plant extract) was calculated by using the formula:

ABTS radical scavenging activity $(\%)=\frac{A b S \text { control }- \text { Abs extractstandard }}{A b S_{\text {control }}} \times 100$

Where, Abs control is the absorbance of ABTS radical in Blank and Abs extract/standard is the absorbance of an ABTS radical solution mixed with extract/ sample.

\section{Ferric reducing antioxidant power assay (FRAP)}

The reducing power was determined by the modified Oyaizu method (1986). Substances which have reduction potential react with potassium ferricyanide to form potassium ferrocyanide, which then reacts with ferric chloride to form ferric-ferrous complex that has an absorption maximum at $700 \mathrm{~nm}$.

The different concentrations of sample alcoholic and aqueous extracts $(300,600$ and $900 \mu \mathrm{g} / \mathrm{ml})$ were mixed with $1 \mathrm{ml}$ of sodium phosphate buffer (pH 6.6) and $1 \mathrm{ml}$ of $1 \%$ potassium ferricyanide. The mixture was incubated at $50^{\circ} \mathrm{C}$ for $20 \mathrm{~min}$. After that, $1 \mathrm{ml}$ of $10 \%$ trichloroacetic acid (w/v) was added and the mixture was centrifuged at $3000 \mathrm{rpm}$ for $10 \mathrm{~min}$. The upper layer (1.5 $\mathrm{ml}$ ) was mixed with $1.5 \mathrm{ml}$ deionized water and $0.1 \mathrm{ml}$ of $0.1 \%$ of ferric chloride, kept for $10 \mathrm{~min}$ and the absorbance was measured at $700 \mathrm{~nm}$ by UV-VIS Shimadzu UV 2450 (Hemalatha et al., 2010; Aparadh et al., 2012). Higher absorbance indicates higher reducing power. The assays were carried out in triplicate and the results are expressed as mean value \pm standard deviation. The extract concentration providing 0.5 of absorbance $\left(\mathrm{EC}_{50}\right)$ was calculated from the graph of absorbance at $700 \mathrm{~nm}$ against extract concentration. Ascorbic acid (4, $8,12,16,20 \mu \mathrm{g} / \mathrm{ml}$ ) was used as standard.

$$
\text { Increase in reducing power }(\%)=\frac{A b s \text { test }- \text { Abs blank }}{A b s \text { blank }} \times 100
$$

Where, Abs test is absorbance of test solution and Abs blank is absorbance of blank. Here reduction of $\mathrm{Fe}\left[(\mathrm{CN})_{6}\right]_{3}$ to $\mathrm{Fe}\left[(\mathrm{CN})_{6}\right]_{2}$ leads to the formation of the intense Perl's Prussian blue complex which gives strong absorbance at $700 \mathrm{~nm}$ with increasing reducing power.

\section{Statistical analysis}

The data generated for each mouse was considered for calculation of Mean \pm S.E.M. for different groups. Statistical evaluation of data was done following Students' t-test. A difference was considered significant at $p \leq 0.05$.

\section{Results}

Total flavonoid content (TFC) and total phenol content (TPC)

The total flavonoid content (TFC) and total phenol content (TPC) was calculated from the absorbance calibration curve generated with different concentrations of Quercetin and Gallic acid respectively which is shown in Table 1.

\section{Hydrogen peroxide radical scavenging}

The HPS activity has usually been determined by following the rate of $\mathrm{H}_{2} \mathrm{O}_{2}$ consumption in an incubation system $\left(\mathrm{H}_{2} \mathrm{O}_{2}+\right.$ scavenger $)$ using the classical UVmethod. The results of the hydrogen peroxide scavenging test of the alcoholic and aqueous extracts of Sida cordifolia in comparison with the standard (ascorbic acid) at $230 \mathrm{~nm}$ is shown in Table 2. The percentage of inhibition against different concentrations of both extracts of the research drug as well as ascorbic acid was used to plot the standard curve which was used to 
calculate the $\mathrm{IC}_{50}(\mu \mathrm{g} / \mathrm{ml})$ of each sample which was determined as $36.189 \pm 0.993,31.297 \pm 2.791$ and 15.503 \pm 1.356 for alcoholic extract, aqueous extract and ascorbic acid respectively.

Table 1. Estimation of total flavonoid content (TFC) and total phenol content (TPC) in Sida cordifolia extracts.

\begin{tabular}{lll}
\hline Tests $($ TFC and TPC) & \multicolumn{2}{c}{ Extract of Sida cordifolia } \\
\cline { 2 - 3 } & Alcoholic & Aqueous \\
\hline $\begin{array}{l}\text { Flavonoid content }(\mu \mathrm{g} \text { Quercetin equivalent / } \mathrm{mg} \text { of extract) following the standard } \\
\text { curve }\left(\mathrm{R}^{2}=0.979\right)\end{array}$ & 15.03 & 6.62 \\
$\begin{array}{l}\text { Phenol content }(\mu \mathrm{g} \text { Gallic acid equivalent / } \mathrm{mg} \text { of extract) following the standard curve } \\
\left(\mathrm{R}^{2}=0.979\right)\end{array}$ & 18.70 & 23.26 \\
\hline
\end{tabular}

Table 2. Hydrogen peroxide scavenging activity of extracts of Sida cordifolia.

\begin{tabular}{llll}
\hline Sample tested & Concentration $(\boldsymbol{\mu g} / \mathbf{m l})$ & \% of inhibition & $\mathbf{I C}_{\mathbf{5 0}}(\boldsymbol{\mu g} / \mathbf{m l})$ from standard curve \\
\hline Alcoholic extract of Sida cordifolia & 24.94 & 17.02 & $36.189 \pm 0.993\left(\mathrm{R}^{2}=0.9754\right)$ \\
& 49.75 & 83.40 & \\
Aqueous extract Sida cordifolia & 74.44 & 199.57 & \\
& 24.94 & 33.62 & \\
& 49.75 & 95.74 & \\
Ascorbic acid (Standard) & 74.44 & 153.19 & \\
& 12.42 & 31.50 & \\
& 24.69 & 93.50 & \\
& 36.81 & 145.50 & \\
& 48.78 & 182.50 & \\
\end{tabular}

Values are represented as Mean \pm SEM.

\section{DPPH radical scavenging assay}

DPPH has been widely used to evaluate the free radical scavenging effectiveness of various antioxidant substances. In the DPPH assay, the antioxidants were able to reduce the stable radical DPPH to the yellowcolored diphenyl-picryl hydrazine at $517 \mathrm{~nm}$. The results are expressed as the $\mathrm{IC}_{50}$ value (the amount of antioxidant necessary to decrease the initial DPPH concentration by $50 \%$ ). The results of the DPPH radical scavenging test of alcoholic and aqueous extracts of Sida cordifolia in comparison with the standard (ascorbic acid) are shown in Table 3. The percentages of inhibition against different concentrations of both extracts of the research drug as well as ascorbic acid were used to plot the standard curve which was used to calculate the $\mathrm{IC}_{50}$ $(\mu \mathrm{g} / \mathrm{ml})$ of each sample which was determined as 1.520 \pm 0.075 in alcoholic extract, $1.027 \pm 0.012$ in aqueous extract of Sida cordifolia and $0.879 \pm 0.273$ in Ascorbic acid respectively.

Table 3. DPPH radical scavenging activity of extracts of Sida cordifolia.

\begin{tabular}{llll}
\hline Sample tested & Concentration $(\mathbf{m g} / \mathbf{m l})$ & \% of inhibition & $\mathbf{I C}_{\mathbf{5 0}}(\mathbf{m g} / \mathbf{m l})$ from standard curve \\
\hline Alcoholic extract of Sida cordifolia & 0.500 & 16.18 & $1.520 \pm 0.075\left(\mathrm{R}^{2}=0.9911\right)$ \\
& 1.000 & 36.27 & \\
Aqueous extract of Sida cordifolia & 2.000 & 64.38 & \\
& 0.500 & 30.59 & $1.027 \pm 0.012\left(\mathrm{R}^{2}=0.9422\right)$ \\
Ascorbic acid (Standard) & 1.000 & 55.33 & \\
& 2.000 & 75.93 & \\
& 0.05 & 3.59 & \\
& 0.10 & 9.97 & \\
& 0.15 & 10.78 & \\
& 0.20 & 14.54 & \\
\hline
\end{tabular}

Values are represented as Mean \pm SEM.

\section{ABTS radical scavenging assay}

In this assay, ABTS is converted to its radical cation by addition of sodium persulfate. This radical cation is blue in color and absorbs light at $734 \mathrm{~nm}$. The ABTS radical cation is reactive towards most antioxidants including phenolics, thiols and vitamin $\mathrm{C}$. During this reaction, the blue ABTS radical cation is converted back 
to its colorless neutral form. The reaction may be monitored spectrophotometrically. This assay is often referred to as the Trolox equivalent antioxidant capacity (TEAC) assay.

The results of the ABTS radical scavenging test of the alcoholic and aqueous extracts of Sida cordifolia in comparison with the standard (Trolox) are shown in Table 4 . The percentage of inhibition against different concentrations of both extracts of the research drug as well as Trolox as Standard was used to plot the standard curve. This curve was used to calculate the $\mathrm{IC}_{50}(\mu \mathrm{g} / \mathrm{ml})$ of each sample which was determined as $332.960 \pm 2.177$ for alcoholic extract, $162.155 \pm 9.736$ for aqueous extract of Sida cordifolia and $6.779 \pm 0.167$ in case of Trolox respectively. It is also observed that inhibition percentage values go on increasing with increases in concentration of research plant extracts in the assay mixture.

Table 4. Percentage of ABTS radical scavenging activity shows by Trolox.

\begin{tabular}{llll}
\hline Sample tested & Concentration $(\boldsymbol{\mu g} / \mathbf{m l})$ & $\mathbf{\%}$ of inhibition & $\mathbf{I C}_{\mathbf{5 0}}(\boldsymbol{\mu g} \mathbf{g} \mathbf{m l})$ from standard curve \\
\hline Alcoholic extract of Sida cordifolia & 200 & 5.86 & $332.960 \pm 2.177\left(\mathrm{R}^{2}=0.9502\right)$ \\
& 300 & 49.14 & \\
Aqueous extract of Sida cordifolia & 400 & 67.86 & \\
& 200 & 57.61 & $162.155 \pm 9.736\left(\mathrm{R}^{2}=0.858\right)$ \\
Trolox (Standard) & 300 & 61.42 & \\
& 400 & 83.25 & \\
& 2.70 & 14.29 & $6.779 \pm 0.167\left(\mathrm{R}^{2}=0.9973\right)$ \\
& 4.05 & 25.00 & \\
& 8.10 & 64.00 & \\
\hline
\end{tabular}

Values are represented as Mean \pm SEM.

\section{Ferric reducing antioxidant power (FRAP) assay}

In this assay the yellow colour of the test solution changes to various shades of green and blue depending upon the reducing power of each compound. The presence of radicals (i.e. antioxidants) causes the conversion of the $\mathrm{Fe}^{3+} /$ ferricyanide complex used in this method to the ferrous form indicated by the formation of pearls Prussian blue at $700 \mathrm{~nm}$, a higher absorbance indicating a higher reducing power.

The results of the FRAP test of the alcoholic and aqueous extracts in comparison with the standard (ascorbic acid) at $700 \mathrm{~nm}$ is shown in Table 5. The percentage of inhibition against different concentrations of both extracts of the research drug as well as ascorbic acid was used to plot the standard curve which was used to calculate the $\mathrm{IC}_{50}(\mu \mathrm{g} / \mathrm{ml})$ of each sample, which was determined as $232 \pm 15.163,179 \pm 53.894$ and 6.627 \pm 0.061 for alcoholic extract, aqueous extract of Sida cordifolia and Ascorbic Acid respectively. It is also observed that inhibition percentage values go on increasing with enhancements in concentration of research plant extracts in the assay mixture.

Table 5. Ferric reducing antioxidant power assay with Sida cordifolia extracts.

\begin{tabular}{llll}
\hline Sample tested & Concentration $(\boldsymbol{\mu g} / \mathbf{m l})$ & \% of Inhibition & $\mathbf{I C}_{\mathbf{5 0}}(\boldsymbol{\mu g} \mathbf{g} \mathbf{m})$ from standard curve \\
\hline Alcoholic extract of Sida cordifolia & 300 & 66.207 & $232 \pm 15.163\left(\mathrm{R}^{2}=0.9992\right)$ \\
& 600 & 142.431 & \\
Aqueous extract of Sida cordifolia & 900 & 211.691 & \\
& 300 & 109.00 & $179 \pm 53.894\left(\mathrm{R}^{2}=0.998\right)$ \\
Ascorbic acid (Standard) & 600 & 264.10 & \\
& 900 & 440.60 & \\
& 4 & 20.78 & $6.627 \pm 0.061\left(\mathrm{R}^{2}=0.997\right)$ \\
& 8 & 63.64 & \\
& 12 & 114.29 & \\
& 16 & 174.03 & \\
& 20 & 224.68 & \\
\hline
\end{tabular}

Values are represented as Mean \pm SEM. 
The obtained $\mathrm{IC}_{50}$ values in respect of the two extracts of Sida cordifolia as well as the standard drug using the various techniques discussed above have been shown in Fig. 1. It is evident that aqueous extract shows higher level of antioxidant activity as compared to the alcoholic extract in all the methods of analysis.

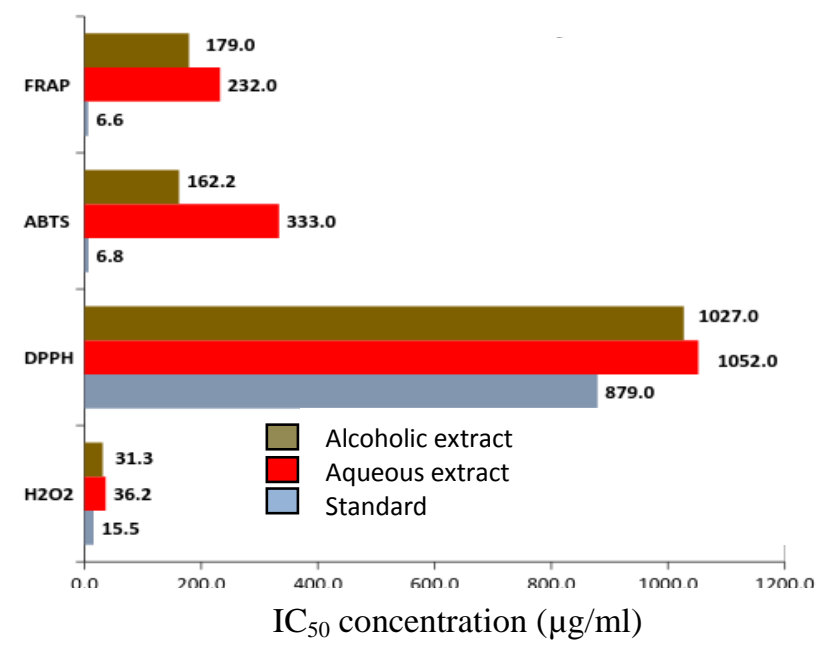

Fig. 1: Comparative $\mathrm{IC}_{50}$ values of Sida cordifolia extracts and standard.

\section{Discussion}

The total phenolic content of the alcoholic root extract was 18.70 Gallic acid equivalents/mg while it was 23.26 for the aqueous extract. Similarly, the total flavonoid content was assessed as 15.03 and 6.62 Quercetin equivalent $/ \mathrm{mg}$ for these two extracts respectively. Thus, the alcoholic extract of Sida cordifolia shows more Quercetin equivalent content indicating higher flavonoids than its aqueous extract. However, its aqueous extract shows more Gallic acid equivalents (higher total phenol content) than its alcoholic extract. Phenolic compounds have redox properties, which allow them to act as antioxidants (Soobrattee et al., 2005). As their free radical scavenging ability is facilitated by their hydroxyl groups, the total phenolic concentration could be used as a basis for rapid screening of antioxidant activity. Flavonoids, including flavones, flavanols and condensed tannins, are plant secondary metabolites, the antioxidant activity of which depends on the presence of free $\mathrm{OH}$ groups, especially 3-OH. Plant flavonoids have antioxidant activity in vitro and also act as antioxidants in vivo (Geetha et al., 2003; Shimoi et al., 1996). Plants rich in secondary metabolites, including phenolics, flavonoids and carotenoids, have antioxidant activity due to their redox properties and chemical structures.
Examination of the $\mathrm{IC}_{50}$ values obtained during Hydrogen Peroxide Radical Scavenging test indicate that when compared with the standard drug ascorbic acid, more than twice the amount of concentrations of the aqueous and alcoholic extracts of the research drug are required for scavenging 50\% Hydrogen peroxides. The free radical scavenging effect in respect of Hydrogen Peroxide was found higher in the aqueous extract at 24.94 and $49.75 \mu \mathrm{g} / \mathrm{ml}$ concentrations than in alcoholic extract while it was lower at $74.44 \mu \mathrm{g} / \mathrm{ml}$ concentration of Sida cordifolia. However, the radical scavenging effect at all observed concentrations for both aqueous and alcoholic extracts of the research drug was quite low in comparison to ascorbic acid.

The high phenolic and flavonoid content is responsible for the bioactivity of these crude extracts. Flavonoids are highly effective scavengers of most oxidizing molecules, including singlet oxygen, and various other free radicals implicated in several diseases Hydrogen peroxide $\left(\mathrm{H}_{2} \mathrm{O}_{2}\right)$, a biologically relevant, non-radical oxidizing species, may be formed in tissues through oxidative processes, but there has been limited information regarding its scavenging by polyphenolic antioxidants. Among reactive oxygen species (ROS), hydrogen peroxide $\left(\mathrm{H}_{2} \mathrm{O}_{2}\right)$ is a relatively stable, non-radical oxidant, which can diffuse across biological membranes. It is produced by 2-electron reduction of molecular oxygen or by dismutation of the superoxide anion radical (Shukla et al., 2009; Bravo, 1998; Agati et al., 2012).

Ascorbic acid or citamin $\mathrm{C}$ has been used as the standard in this research since it is a water-soluble free radical scavenger. Moreover, it regenerates vitamin $\mathrm{E}$ in cell membranes in combination with compounds capable of donating reducing equivalents. Vitamin $\mathrm{C}$ changes to the ascorbate radical by donating an electron to the lipid radical in order to terminate the lipid peroxidation chain reaction (Nimse et al., 2015). The research plant extracts reduce the DPPH radical to corresponding hydrazine when they react with hydrogen donors. It is noticed that aqueous and alcoholic extracts of the research drug are required in higher concentrations than the ascorbic acid standard for performing antioxidant activity measured by assessing the concentration required for $50 \%$ scavenging of the DPPH radical, i.e. $\mathrm{IC}_{50}(\mu \mathrm{g} / \mathrm{ml})$. The aqueous extract having higher phenolics exhibits higher scavenging activity during this test as compared to the alcohol extract. The free radical scavenging effect assessed as percentage inhibition was found to be 75.93 in the aqueous extract at $2.0 \mathrm{mg} / \mathrm{ml}$ concentration as compared to $64.38 \%$ at same concentration in the 
alcoholic extract. It is also observed that inhibition percentage increases commensurate with increases in concentration of research plant extracts in the assay mixture during DPPH test.

An antioxidant has the ability to donate a hydrogen atom that will quench the stable free radical which is associated with a change in absorption which can be followed calorimetrically. The pre-formed radical monocation of $\left(\mathrm{ABTS}^{\circ+}\right)$ is generated by oxidation of ABTS with potassium per-sulfate and is reduced in the presence of hydrogen-donating antioxidants. The influences of both the concentration of antioxidant and duration of reaction are taken into account when determining the antioxidant activity. It is observed that for any particular level of antioxidant activity, higher concentrations of aqueous and alcoholic extracts of the research drug are required than the standard ascorbic acid. This phenomenon is clearly observed when measuring the antioxidant activity for scavenging 50\% ABTS radicals as evaluated in the form of $\mathrm{IC}_{50}(\mu \mathrm{g} / \mathrm{ml})$.

The free radical scavenging effect measured as percentage inhibition in case of the stable ABTS was found to be 61.42 in the aqueous extract at $300 \mu \mathrm{g} / \mathrm{ml}$ concentration as compared to 49.14 in alcoholic extract at the same concentration of Sida cordifolia. The standard drug Trolox showed high inhibition at very low values of concentration in comparison to both the aqueous and alcoholic extracts. Since Trolox is a watersoluble analog of vitamin $\mathrm{E}$, it is used as an antioxidant like vitamin $\mathrm{E}$ in biological or biochemical applications to reduce oxidative stress or damage.

FRAP is an electron transfer based total antioxidant assay, also called redox linked colorimetric method. There is an increase in absorbance at a pre specified wavelength as an antioxidant reacts with chromogenic reagent (Fe (II)) (Everest and Ozturk, 2005). The percentage of inhibition at $300 \mu \mathrm{g} / \mathrm{ml}$ concentrations was found to be 66.207 in case of alcoholic and 109.00 for aqueous extract, while it was $142.431 \%$ and $264.10 \%$ in case of alcoholic and aqueous extracts respectively at $600 \mu \mathrm{g} / \mathrm{ml}$ concentration. Thus, the aqueous extract of the research drug consistently showed higher inhibition and, therefore, higher antioxidant activity during this study. The percentage inhibition as well as the $\mathrm{IC}_{50}$ values clearly indicated that the standard (ascorbic acid) showed very low $\mathrm{IC}_{50}$ levels indicating its very high antioxidant capacity in comparison with both the alcoholic and aqueous extracts.

\section{Conclusion}

The evaluation of in vitro antioxidant activity of the aqueous and alcoholic extracts of Sida cordifolia showed substantial and significant free radical scavenging activity in both the extracts which is compared to that of the standard drug during the study. The aqueous extract exhibits a higher level of activity than the alcoholic extract in all the antioxidant assessment techniques. This significant pronounced antioxidant activity of aqueous extract may be due to the presence of higher concentrations of phenolic compound in it as compared to the alcoholic extract. This in vitro assessment of the antioxidant properties of Sida cordifolia validates and confirms its free radical scavenging activity also known as Rasayan Karma as described in the Ayurvedic system of medicine.

\section{Conflict of interest statement}

Authors declare that they have no conflict of interest.

\section{Acknowledgement}

This research work was supported by grants from the Department of Science and Technology, Government of West Bengal and the authors are grateful for this support. We are thankful to Shri Saumya Kanti Sasmal, Ph.D. Scholar, Department of Dravyaguna, Institute of Post Graduate Ayurvedic Education and Research, Kolkata for providing the necessary help during the experimental work.

\section{References}

Agati, G., Azzarello, E., Pollastri, S., Tattini, M., 2012. Flavonoids as antioxidants in plants: location and functional significance. Plant Sci. 196, 67-76.

Anil, K.V., Babul, D., Rama, T., 2011. Evaluation of antiulcerogenic properties from the root of Flemingia strobilifera. J. Basic Clin. Pharm. 2(1), 33-39.

Aparadh, V.T., Naik, V.V., Karadge, B.A., 2012. Antioxidative properties (TPC, DPPH, FRAP, Metal chelating ability, Reducing power and Tac) within some Cleome species. Ann. Bot. (Roma). 2, 49-56.

Baba, S.A., Malik, S.A., 2015. Determination of total phenolic and flavonoid content, antimicrobial and antioxidant activity of a root extract of Arisaema jacquemontii. J. Taibah Univ. Sci. 9, 449-454.

Basniwal, P.K., Suthar, M., Rathore, G.S., Gupta, R., Kumar, V., Pareek, A., Jain, D., 2009. In-vitro antioxidant activity of hot aqueous extract of Helicteres isora Linn. fruits. Natural Prod. Rad. 8(5), 483-487.

Bernays, E.A., Driver, G.C., Bilgener, M., 1989. Herbivores and plant tannins. Adv. Ecol. Res. 19, 263-302. 
Bravo, L., 1998. Polyphenols: chemistry, dietary sources, metabolism and nutritional significance. Nutr. Rev. 56, 317-333.

Chang, C., Yang, M., Wen, H., Chern, J., 2002. Estimation of total flavonoid content in propolis by two complementary colorimetric methods. J. Food Drug Anal. 10 (2002), 178182.

Chatterjee, A., Pakrashi, S.C., 1992. The Treatise on Indian Medicinal Plants. Vols. 2 and 3. Publications and Information Directorate, CSIR, New Delhi.

Chung, K.T., Wong, T.Y., Huang, Y.W., Lin, Y., 1998. Tannins and human health: a review. Crit. Rev. Food Sci. Nutr. 38, 421-464.

Everest, A., Ozturk, E., 2005. Focusing on the ethnobotanical uses of plants in Mersin and Adana provinces (Turkey). J. Ethnobiol. Ethnomed. 1, 6. DOI: 10.1186/1746-4269-1-6.

Frankel, E.N., Waterhouse, A.L., Kinsella, J.E., 1993. Inhibition of human LDL oxidation by resveratrol. Lancet. 341 (8852), 1103-1104.

Geetha, S., Sai-Ram, M., Mongia, S.S., Singh, V., Ilavazhagan, G., et al., 2003. Evaluation of antioxidant activity of leaf extract of sea buckthorn (Hippophae rhamnoides L.) on chromium (VI) induced oxidative stress in albino rats. J. Ethnopharmacol. 87, 247-251.

Harborne, J.B., 1984. Phytochemical Methods: A Guide to Modern Technique of Plant Analysis. $2^{\text {nd }}$ Edition. Chapmann and Hall, London.

Hemalatha, S., Lalitha, P., Arulpriya, P., 2010. Anti-oxidant activities of the extracts of the aerial roots of Pothos aurea (Linden ex Andre). Der. Pharma. Chemica. 2(6), 84-89.

Jain, A., Choubey, S., Singour, P.K., Rajak, H., Pawar, R.S., 2011. Sida cordifolia (Linn.) - An overview. J. Appl. Pharmaceut. Sci. 1(2), 23-31.

Keser, S., Celik, S., Turkoglu, S., Yilmaz, O., Turkoglu, I., 2012. Hydrogen peroxide radical scavenging and total antioxidant activity of Hawthorn. Chem. J. 2(1), 9-12.

Kirtikar, K.R., Basu, B.D., 1989. Indian Medicinal Plants. Vol. 2. Allahabad. pp.312-313.

Miyake, K., Mickley, L., Litman, T., Zhan, Z., Robey, R., Cristensen, B., Brangi, M., Greenberger, L., Dean, M., Fojo, T., Bates, S.E., 1999. Molecular cloning of cDNAs which are highly overexpressed in mitoxantroneresistant cells: demonstration of homology to $\mathrm{ABC}$ transport genes. Cancer Res. 59(1), 8-13.

Nimse, S.B., Pal, D.K., 2015. Free radicals, natural antioxidants, and their reaction mechanisms. RSC Adv. 5, 27986-28006.

Nishaa, S., Vishnupriya, M., Sasikumar, J.M., Hephzibah P.C., Gopalakrishnan, V.K., 2012. Antioxidant activity of ethanolic extract of Maranta arundinacea L. tuberous rhizomes. Asian J. Pharmaceut. Clin. Res. 5(4), 85-88.

Oyaizu, M., 1986. Studies on product of browning reaction prepared from glucose amine. Jpn. J. Nutr. 44, 307-315.

Özcelik, B., Lee, J.H., Min, D.B., 2003. Effects of light, oxygen and $\mathrm{pH}$ on the 2,2-diphenyl-1-picrylhydrazyl (DPPH) method to evaluate antioxidants. J. Food Sci. 68, 487-490.

Re, R., Pellegrini, N., Proteggente, A., Pannala, A., Yang, M., Rice-Evans, C., 1999. Antioxidant activity applying an improved ABTS radical cation decolourization assay. Free Rad. Biol. Med. 26, 1231-1237.

Sharma, P.C., Yelne, M.B., Dennis, T.J., 2001. Database on Medicinal Plants Used in Ayurveda. Vol. 8. Central Council for Research in Ayurveda and Siddha, Department of Indian System of Medicine. Govt. of India, New Delhi. pp.42-58.

Sharma, P.V., 1995. Introduction to Dravyaguna (Indian Pharmacology). Vol. 2. Chaukhamba Orientalia, Varanasi, India. pp.734-736.

Shastri, S.N., 1988. Charak Samhita (Chikitsa Sthanam), Chapter 3. Chaukhamba Bharati Academy, Varanasi, India. pp. 115.

Shimoi, K., Masuda, S., Shen, B., Furugori, M., Kinze, N., 1996. Radioprotective effects of antioxidative plant flavonoids in mice. Mutat. Res. Fund. Mol. 350, 153-161.

Shukla, S., Mehta, A., Bajpai, K.V., Shukla, S., 2009. In vitro antioxidant activity and total phenolic content of ethanolic leaf extract of Stevia rebaudiana Bert. Food Chem. Toxicol. 47, 2338-2343.

Soobrattee, M.A., Neergheen, V.S., Luximon-Ramma, A., Aruoma, O.I., Bahorun, O.T., 2005. Phenolics as potential antioxidant therapeutic agents: mechanism and actions, Mutat. Res. Fund. Mol. 579, 200-213.

Tupe, R.S., Kemse, N.G., Khaire, A.A., 2013. Evaluation of antioxidant potentials and total phenolic contents of selected Indian herbs powder extracts. Ind. Food Res. J. 20(3), 1053-1063.

Usha Sri, B., Ibrahim, M., Mahendra Kumar, C.B., 2012. Antioxidant activity and total flavonoids content of different parts of Azadirachta indica A. Juss. J. Med. Plants Res. 6(46), 5737-5742.

Wang, S. Y., Jiao, H., 2000. Scavenging capacity of berry crops on superoxide radicals, hydrogen peroxide, hydroxyl radicals, and singlet oxygen. J. Agric. Food. Chem. 48(11), 5677-5684.

Živković, J., Zeković, Z., Mujić, I., Vidović, S., Cvetković, D., Lepojević, Ž., Nikolić, G., Trutić, N., 2010. Scavenging capacity of superoxide radical and screening of antimicrobial activity of Castanea sativa Mill. extracts. Czech. J. Food. Sci. 28(1), 61-68.

\section{How to cite this article:}

Gupta, M., Paul, S., Karmakar, N., Sasmal, S., Chowdhury, S., 2016. Free radical scavenging activity of Sida cordifolia Linn. extracts measured by hydrogen peroxide, DPPH, ABTS and ferric reducing antioxidant methods. Int. J. Curr. Res. Biosci. Plant Biol. 3(8), 114-122. doi: http://dx.doi.org/10.20546/ijcrbp.2016.308.018 